\title{
Assessment of Knowledge, Attitude and Practices Among Solid Waste Collectors in Lideta Sub-city on Prevention of Occupational Health Hazards, Addis Ababa, Ethiopia
}

\author{
Fikrom Gebremedhin ${ }^{1,}$, Mesfin Kote Debere ${ }^{2}$, Abera Kumie ${ }^{1}$, Zemedu Mehamed Tirfe ${ }^{2}$, \\ Andamlak Gizaw Alamdo ${ }^{3}$ \\ ${ }^{1}$ School of Public Health, College of Health Sciences, Addis Ababa University, Addis Ababa, Ethiopia \\ ${ }^{2}$ Epidemiology and Biostatstics Unit, Department of Public Health, College of Medicine and Health Sciences, Arba Minch University, Arba \\ Minch, Ethiopia \\ ${ }^{3}$ Department of Public Nursing, Arba Minch Health Sciences College, Arba Minch, Ethiopia
}

Email address:

fikromgm@yahoo.com (F. Gebremedhin), messi.kid@gmail.com (M. K. Debere), aberakumie2@Yahoo.com (A. Kumie), zemedu2003@gmail.com (Z. M. Tirfe), gizandal@gmail.com (A. G. Alamdo)

\section{To cite this article:}

Fikrom Gebremedhin, Mesfin Kote Debere, Abera Kumie, Zemedu Mehamed Tirfe, Andamlak Gizaw Alamdo. Assessment of Knowledge, Attitude and Practices Among Solid Waste Collectors in Lideta Sub-city on Prevention of Occupational Health Hazards, Addis Ababa, Ethiopia. Science Journal of Public Health. Vol. 4, No. 1, 2016, pp. 49-56. doi: 10.11648/j.sjph.20160401.17

\begin{abstract}
Municipal solid waste workers are exposed to a number of pathogens (bacteria, fungi, viruses, parasites and cysts), toxic substances, chemicals that come from the waste itself and from its decomposition. While standards and norms for handling municipal solid waste in industrialized countries have reduced occupational and environmental impacts significantly, the risk levels are still very high in most developing countries including Ethiopia because of inadequate understanding of the magnitude of the problem. Despite the severity of occupational health hazards encounter by solid waste collectors their provision, knowledge and usage of personnel protective equipment is low and there is no adequate and credible evidence on occupational health risks of solid waste collectors in Ethiopia. Therefore, this study was aimed to assess the knowledge, attitude and practices of solid waste collectors towards prevention of occupational health hazards in Lideta sub-city in Ethiopia. A cross-sectional survey was conducted among four hundred six solid waste collectors for this work. The data was collected by using semi-structured questionnaire and observational checklist, which was completed from December 2014 to February 2015. The data was entered into epi info version 3.5.1 and exported to SPSS 20 version for analysis. Multiple logistic regression analysis had been performed. Adjusted odds ratio with confidence interval had been computed to see the presence of association between the dependent and selected independent variables. The results on this finding were reported using different descriptive statistics. The response rate of this study was $94.8 \%$. Female respondents accounted $69.7 \%$. The mean age of the study subjects was 35 years, which varied from 17 to 65 years. About $60.8 \%$ of the study participants had satisfactory knowledge on preventing occupational health risks associated with solid waste handling. Most (75.9\%) of the solid waste collectors had favorable attitude while only $37.2 \%$ of them had safe practice on preventing occupational health hazards. As compared to workers who were satisfied on their job, odds of having safe occupational health practice were 2.8 higher $(\mathrm{AOR}=$ 2.8, 95\% CI: 1.84 - 4.26). The knowledge and attitudes of workers about prevention of occupational health hazards were moderate but the magnitude of having safe occupational health practice was very low. So, implementation of basic occupational health services with provision of personal protective equipment's and supervising waste handlers on appropriate utilization is advisable.
\end{abstract}

Keywords: KAP, Waste Collectors, Occupational Health, Ethiopia

\section{Background}

Municipal solid waste (MSW) handling and disposal is a growing environmental and public health concern. The collection of household waste is a hard job, which involves working on a vehicle that moves through traffic throughout the year. It also requires repeated heavy physical activity, 
such as the manual lifting and handling of heavy bins (M. Athanasiou, Makmxnes et al. 5 September 2010; Oxford university 2005). Municipal solid waste workers are exposed to a number of pathogens (bacteria, fungi, viruses, parasites and cysts), toxic substances, chemicals that come from the waste itself and from its decomposition, as well as vehicle exhaust fumes, noise, extreme temperatures and ultraviolet radiation (S. 2005). In low income countries solid waste collectors are likely to have a low socio-economic status and the medical problems of these workers are further compounded by various socio-economic factors such as poverty, lack of education, poor housing conditions and poor diet. Farther more, these groups of workers are exposed directly and without adequate protection to MSW, they are more susceptible to occupational hazards (Sarkar 2003).

Addis Ababa per capita solid waste generation rate is $0.45 \mathrm{k} . \mathrm{g} / \mathrm{c} /$ day and more than 200,000 tons of waste is collected each year. From this amount of waste $76 \%$ is produced from households; $18 \%$ from institutions, commercial centers, factories \& hotels and the rest $6 \%$ is from street sweeping (Addis Ababa city solid waste management Agency February 2010). A research done in Addis Ababa revealed that only $43.6 \%$ of the solid waste collectors were using personal protective equipment (PPE) all the time while they were on duty which might result in increasing the probability of occupational health risks (Bogale 2012).

\subsection{Knowledge and Attitude of Solid Waste Collectors About Occupational Health Practices}

According to a research done on health risk reduction behaviors, model scavengers exposed to solid waste in Thailand, most solid waste collectors had low level of knowledge and alertness on occupational health risks (Phiman E 2011). Despite the severity of occupational health hazards encounter by solid waste collectors their provision and usage of PPE is low. A study done in Colombo municipal council workers revealed that, gloves and boots were available for $44 \%$ of solid waste collectors and the usage is only $25 \%$ (Mudalige OM and Dharmathilake AD 2000). A study done in Hebron and Bethlehem reveals that most of the solid waste collectors did not use PPE i.e. $98.6 \%$ of them do not use face mask; $78.9 \%$ do not use rubber boot; $45 \%$ do not use protective gloves; and $85.5 \%$ do not use over all protective materials (Ahmed 2004). A study done in Addis Ababa revealed that, only $43.6 \%$ of the solid waste collectors were using PPE while they are on duty and of these, only $22.5 \%$ of them reported as not using it consistently while they are on duty. Not having access (83.7\%), discomfort $(25.6 \%)$ and to save time $(12.8 \%)$ were the main reasons mentioned by them for not using the PPE (Bogale 2012).

A study done in Port Hartcourt Metropolis in Nigeria about the attitude of solid waste collectors towards safe occupational practice revealed that, $76.3 \%$ agreed that they had sustained injuries from sharp objects in the course of packing refuse with bare hands and $26.2 \%$ agreed that their PPE were of the right quality and suitable to the task (Inyang M 2009).

\subsection{Factors Affecting Occupational Health Practices of Solid Waste Collectors}

The training of workers on occupational health and safety issues, as well as workers' rights within the work place has been an important part of improving working conditions. Workers prior to commencement of new assignments should receive adequate training and information enabling them to understand the hazards of work and to protect their health from ambient factors that may present. The training must cover knowledge of materials, equipment's and tools; known hazards in the operations and how to control these hazards; potential risks to health; hygiene requirements; wearing and use of PPE; and appropriate extremes, incidents and accidents (WHO 1998; Kiwekete HM 2009; ILO June 24 2003). A research done in Addis Ababa revealed that, only $20.8 \%$ of the solid waste collectors had training before starting the waste collection job and $57.3 \%$ had on job training after they engaged to this job. According to this research female waste collectors account $71.2 \%$ and the mean age of the waste collectors was 33 years with 18 and 70 years minimum and maximum respectively. The mean monthly income for the research participants was 400 Ethiopian birr with range of 200 to 900 birr (Bogale 2012).

There is shortage of data on occupational health risks, which is now becoming a concern given for scaling up for development in Ethiopia. Specifically there is inadequate credible evidence on Knowledge, attitude and practice (KAP) on prevention of health risks and associated factors among solid waste collectors in the country to design new strategies to address the problem for both governmental and nongovernmental organizations. Therefore this study was aimed to assess knowledge, attitude and practices of solid waste collectors about prevention of occupational health risks and associated factors in Lideta sub-city, Addis Ababa, Ethiopia.

\section{Methods}

\subsection{Study Area}

A cross-sectional survey had been conducted from December 15, 2014 to February 30, 2015 in Lideta sub-city, Addis Ababa, Ethiopia. The sub-city had a total population of 259,450 and is organized by two layers of government i.e. the sub-city and 10 woredas (lower level administration) under Lideta sub-city administration. Currently 37 micro and small scale enterprises are emerged to participate in primary solid waste collection. The emerged solid waste collection associations have tried to collect garbage from households and transport it to the municipal waste containers and transfer station. The sub-city is divided in to 37 zones and each comprises 120 to 1200 households in each zone. At each zone one association is assigned to work on solid waste collection and there were a total of 428 solid waste collectors in the sub-city and about 406 of them were considered for analysis in this study while the remaining 22 of them were not considered for analysis. The waste collectors are responsible for the collection of household wastes only. 


\subsection{Data Collection}

Ethical clearance was obtained from the Institutional Review Board of Addis Ababa University College of Health Sciences. Formal letter was written to Lideta Sub City cleansing management office and written letter had been given to each woreda. Written consent had been taken from each respondent. Confidentiality was maintained by omitting their names and personal identification. Privacy was maintained by arranging quite place for the interviewer and the study participant to protect them exposing other parties. The study participants had the right to withdraw at any time. A semi-structured interview questionnaire was used for this study. The questions related to KAP included 26 items. These items were developed by the authors after reviewing similar published articles. For knowledge, 10 items were developed having yes/no responses. Attitudes were assessed using 10 questions having strongly agree/agree/disagree/ strongly disagree /no opinion as responses. Actual practices were assessed by a participant observation checklist (6 items) concerning wearing personal protection, correct disposal of sharps and other waste, personal hygiene having yes/ no responses. The questionnaire had been prepared in English and then translated into the local language (Amharic) to collect data and finally the Amharic version also re-translated back to English to insure consistency. Training had been given to data collectors and supervisors prior to data collection period for one day.

The overall knowledge score of each worker about the studied prevention of occupational health hazards was estimated as follows: Each question of the ten knowledge questions was given one point if the answer was correct and zero point if the answer was wrong, and the total points were calculated for each worker by summing up the points he/she obtained. The overall level of knowledge was considered unsatisfactory/low when the worker correctly answered below five questions, and satisfactory/high when correctly answering five and more questions. The overall level of attitude was considered unfavorable when the worker correctly answered below five questions, and favorable when correctly answering five and more attitude questions. The attitude scores were dichotomized to favorable and unfavorable to compare our findings with those of other studies. The overall level of practice was considered unsafe when the worker correctly answered below three questions, and safe when correctly answering five and more practice questions. A similar assumption was followed by Hafiz O. Ahmed (Hafiz O. Ahmed, 2010).

\subsection{Statistical Methods}

The data was entered into EPI- INFO version 3.5.1 and exported to Statistical Package for Social Science (SPSS) version 20 for analysis. Frequencies, percentages, means and ranges were calculated for appropriate variables. Adjusted odds ratio (AORs) with confidence interval (CI) had been computed to see the presence of association between the dependent and selected independent variables. Chi-square test had been calculated to relate the three KAP scores with duration of work experience and training received. Multiple logistic regression analysis was used to determine the most important predictors of the practice of workers towards prevention of occupational health hazards. The independent variables used were age, sex, duration of work experiences, years of education, and attending a training course about occupational health and safety. The dependent variables that were considered in this study were knowledge, attitude and practice (KAP). A p-value of less than 0.05 was taken as the statistical level of significance.

\section{Results}

\subsection{Socio-Demographic Characteristics of the Respondents}

A total of four hundred six (406) solid waste handlers were participated in the study yielding the response rate $94.8 \%$. The majority of the respondents were female which accounts $69.7 \%$ and the mean age of the respondents were 35 years with 17 and 65 years minimum and maximum ages respectively (see the other socio-demographic characteristics in table 1).

Table 1. Socio-demographic characteristics of the respondents in Lideta subcity, Addis Ababa, Ethiopia 2015 (N=406).

\begin{tabular}{lll}
\hline Characteristics & Frequency & Percent \\
\hline Age (Years) & 38 & \\
$<25$ & 95 & 9.4 \\
$25-34$ & 160 & 23.4 \\
$35-44$ & 85 & 39.4 \\
$45-54$ & 28 & 20.9 \\
$\geq 55$ & & 6.9 \\
Sex & 123 & \\
Male & 283 & 30.3 \\
Female & & 69.7 \\
Marital status & 116 & \\
Single & 170 & 28.6 \\
Married & 40 & 41.9 \\
Divorced & 15 & 9.9 \\
Separated & 65 & 3.7 \\
Widowed & & 16 \\
Educational status & 151 & \\
Illiterate & 68 & 37.2 \\
Can read and write & 81 & 16.7 \\
Grade 1-4 & 106 & 20 \\
Grade 5-12 & & 26.1 \\
Duration of work (years) & 26 & 6.4 \\
$<2$ & 90 & 22.2 \\
2 - 4 & 170 & 41.9 \\
5 - 9 & 120 & 29.5 \\
$\geq 10$ & &
\end{tabular}

\subsection{Knowledge and Attitude of Waste Handlers About Occupational Health Practices}

According to operational definition settled, the individual response was counted and the mean was calculated to classify respondents as knowledgeable and not knowledgeable based on the knowledge score. Our findings showed that, overall, majority of the respondents 247 $(60.8 \%)$ had satisfactory knowledge and the rest $159(39.2 \%)$ 
had not satisfactory knowledge. The majority of the respondents answered wearing glove, mask, apron, and boots as a means of preventing methods of occupational health risks. About $300(73.9 \%)$ of the waste handlers knew about PPEs and the rest 106 (26.1\%) didn't knew about PPEs. Solid waste handlers were asked about receiving training before engaging to this work, and only about $173(42.6 \%)$ of them received training before engaging to this work and of which about $19(4.7 \%)$ were trained by their association, 119 $(29.3 \%)$ by governmental organization and the rest $35(8.6 \%)$ by different non-governmental organizations (NGOs). Concerning on job training, 190 of the respondents received training while they were on duty, of this 145 (76.3\%) of them were trained by governmental organization and the rest 45 $(23.7 \%)$ were trained by NGOs. Based on our cut of point set in the operational definition among questions prepared to assess attitude of respondents, majority 308 (75.9\%) of the study participants had favorable attitude and the rest 98 (24.1\%) had unfavorable attitude towards occupational health risks prevention (Table 2).

Table 2. Distribution of solid waste collectors according to their responses to attitude questions for preventing occupational health risks in Lideta sub city, Addis Ababa, Ethiopia, 2015.

\begin{tabular}{|c|c|c|c|c|c|}
\hline \multirow{2}{*}{ Question } & \multicolumn{5}{|l|}{ Response } \\
\hline & Strongly agree & Agree & No opinion & Disagree & Strongly disagree \\
\hline Wearing glove can reduce damage to your hand & $95(23.4)$ & $181(44.6)$ & $110(27.1)$ & $13(3.2)$ & $7(1.7)$ \\
\hline Wearing mask can reduce damage to respiratory organs & $96(23.6)$ & $174(42.9)$ & $117(28.8)$ & $16(3.9)$ & $3(0.7)$ \\
\hline Wearing rubber boots can reduce damage to feet & $131(32.3)$ & $163(40.1)$ & $93(22.9)$ & $19(4.7)$ & 0 \\
\hline Wearing apron can reduce physical damage to body & $138(34)$ & $166(40.9)$ & $84(20.7)$ & $16(3.9)$ & $2(0.5)$ \\
\hline Having shower after work reduce diarrheal diseases & $167(41.1)$ & $132(32.5)$ & $100(24.6)$ & $7(1.7)$ & 0 \\
\hline Working with clean cloth can prevent dermal diseases & $154(37.9)$ & $139(34.2)$ & $103(25.4)$ & $9(2.2)$ & $1(0.2)$ \\
\hline Changing cloth after work gives you aesthetical satisfaction & $166(40.9)$ & $133(32.8)$ & $96(23.6)$ & $9(2.2)$ & $2(0.4)$ \\
\hline
\end{tabular}

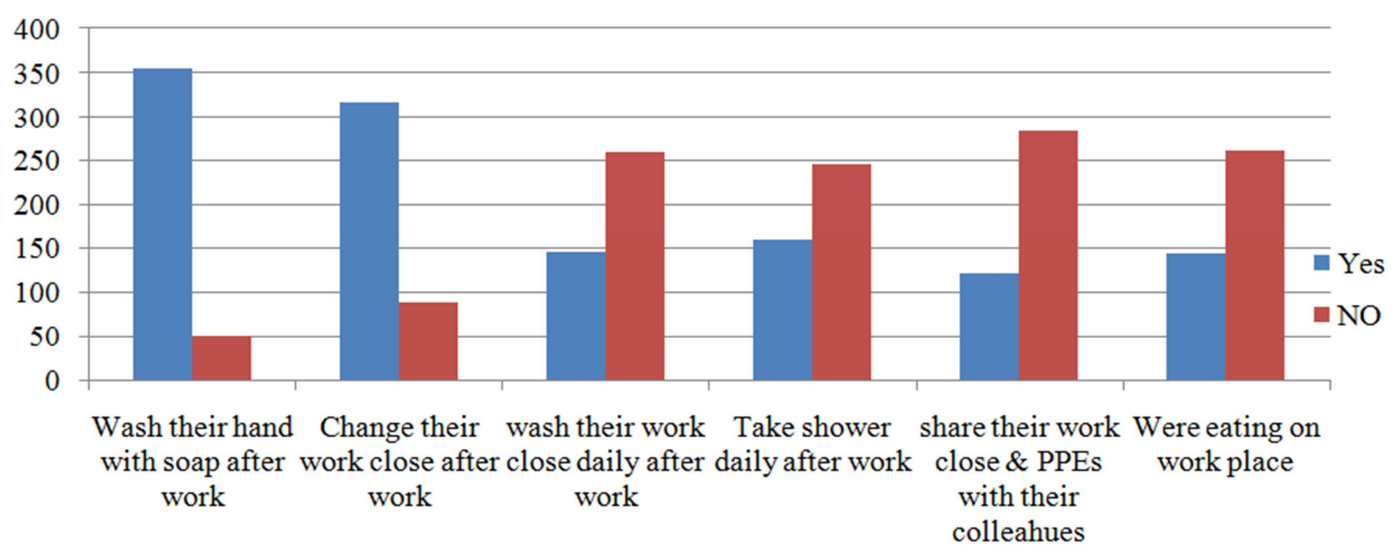

Figure 1. Personal hygiene practices of the respondents in Lideta Sub-City, Addis Ababa, Ethiopia, 2015.

\subsection{Practices of Waste Handlers About PPEs and Their Personal Hygiene}

Our findings showed that, only $151(37.2 \%)$ of waste collectors had safe overall practice related to occupational health hazards. About 286 (70.4\%) of the respondents had PPEs like glove, facemask, boots, and apron but only 15 $(3.7 \%)$ of the waste collectors reported as they had all types of PPEs. About $228(55 \%)$ of the waste collectors were reported using PPEs while they were on duty. Among the non-users of PPEs, about 112 (61.9\%) of them were failed to use because they didn't have PPEs, $12(6.6 \%)$ lack of knowledge, 39 (21.5\%) because of discomfort, $3(1.7 \%)$ negligence, and $15(8.3 \%)$ to save time. According to the direct observation made during this study, among 406 solid waste handlers, only 190 (46.8\%) of them were using gloves during survey. The types of gloves they used, $45(23.7 \%)$ were new, $151(79.5 \%)$ were water proof, $102(53.7 \%)$ were perforated and $110(57.9 \%)$ were well-dressed. Only 68 and 72 waste handlers were utilize facemask and boots at the time of observation respectively.

The Ethiopian immunization policy was updated in 2007. Women of reproductive age group (15-49 years age) are the targets for the Tetanus Toxoid vaccine (TT) (Federal Ministry of Health of Ethiopia, 2010). Only 49 (12.1\%) solid waste handlers had tetanus toxoid vaccine after engaged to this work and the source of the vaccine was $47(95.8 \%)$ from governmental organization and $2(5 \%)$ by themselves. The remaining 357 $(87.9 \%)$ were not taking tetanus TT vaccine; and about 95 (26.5\%) not taking vaccine because of lack of knowledge, 254 (70.9\%) had no access to vaccine, and $9(2.5 \%)$ because of negligence. The study participants were also interviewed on some of their personal hygiene practices. Accordingly, $355(82.5 \%)$ waste handlers were washing their hand with soap after duty and $122(30 \%)$ of them were share their working closes and PPEs with their colleagues. (Figure 1). 


\subsection{Types and Status of Push Carts and Waste Collection Sacks}

The majority of push carts were made from metal which accounts $62.4 \%$ and the rest were made up of wood. One hundred seventy five of observed push carts were easily movable and the rest 82 were not movable (either due to their size or the types of the wheel they have). These push carts were also observed for the smoothness of its general body parts. So that, $72.7 \%$ of these push carts were not smooth. Out of 334 observed waste collection sacks, 289 were old and 162 were perforated at the time of observation.

\subsection{Multiple Logistic Regression Analysis of Factors Affecting Practice of Respondents on Occupational Health Hazards}

To identify practice predictors both bivariate and multiple linear logistic regression was done on different selected variables. Results of the multiple logistic regression analysis (Table 3) showed that the variables years of education, age, job satisfaction, overall level of knowledge and duration of work experiences were the most important variables influencing the overall occupational health practices of the workers. Workers who were satisfied on their job had 2.8 times more safe occupational health practices $(\mathrm{AOR}=2.8$, 95\% CI: 1.84 - 4.26) (Table 3).

Table 3. Results of Multiple Logistic Regression Analysis for the Total Score of Occupational Health Practices for different explanatory variables.

\begin{tabular}{|c|c|c|c|c|}
\hline \multirow{2}{*}{ Characteristics } & \multicolumn{2}{|c|}{ Occupational health practices } & \multirow{2}{*}{ COR (with $95 \%$ CI) } & \multirow{2}{*}{ AOR (with 95\% CI) } \\
\hline & Safe n (\%) & Unsafe n (\%) & & \\
\hline \multicolumn{5}{|l|}{ Educational status } \\
\hline Illiterate & $72(17.73 \%$ & $80(19.70)$ & 1.00 & 1.00 \\
\hline Read and write & $26(6.40 \%)$ & $40(9.85 \%)$ & $0.72(0.40$ to 1.30$)$ & $0.82(0.64-1.16)$ \\
\hline Grade 1-4 & $18(4.43 \%)$ & $62(15.27 \%)$ & $0.33(0.18$ to 0.60$)$ & $0.47(0.03-1.1)$ \\
\hline Grade $5-12$ & $35(8.62 \%)$ & $73(17.98 \%)$ & $0.54(0.32$ to 0.89$)$ & $1.14(1.01-2.55)^{*}$ \\
\hline Male & $48(11.82 \%)$ & $75(18.47 \%)$ & $1.12(0.73$ to 1.73$)$ & $1.29(0.77-3.14)$ \\
\hline Female & $103(25.4 \%)$ & $180(44.33 \%)$ & 1.00 & 1.00 \\
\hline \multicolumn{5}{|l|}{ Age (Years) } \\
\hline$<25$ & $18(4.43 \%)$ & $20(4.93 \%)$ & 1.00 & 1.00 \\
\hline $25-34$ & $35(8.62 \%)$ & $60(14.78 \%)$ & $0.65(0.30$ to 1.39$)$ & $0.76(0.50$ to 2.19$)$ \\
\hline $35-44$ & $41(10.10 \%)$ & $120(29.56 \%)$ & $0.34(0.18$ to 0.79$)$ & $0.47(0.38$ to 0.97$)$ \\
\hline $45-54$ & $39(9.61 \%)$ & $45(11.08 \%)$ & $0.96(0.45$ to 2.08$)$ & $1.09(0.85$ to 3.23$)$ \\
\hline \multicolumn{5}{|c|}{ Having supervision for workers } \\
\hline Yes & $49(12.07 \%)$ & $90(22.17 \%)$ & $0.88(0.58$ to 1.35$)$ & \\
\hline No & $102(25.1 \%)$ & $165(40.64 \%)$ & 1.00 & \\
\hline \multicolumn{5}{|l|}{ Job satisfaction } \\
\hline Yes & $100(24.6 \%)$ & $105(25.86 \%)$ & $2.31(1.10$ to 4.94$)$ & $2.8(1.84-4.26) *$ \\
\hline No & $51(12.56 \%)$ & $150(36.95 \%)$ & 1.00 & 1.00 \\
\hline \multicolumn{5}{|c|}{ Overall level of knowledge } \\
\hline Satisfactory & $119(29.3 \%)$ & $128(31.35 \%)$ & $3.67(2.33$ to 5.85$)$ & $4.25(3.07-8.89)^{*}$ \\
\hline Unsatisfactory & $32(7.88 \%)$ & $127(31.28 \%)$ & 1.00 & 1.00 \\
\hline \multicolumn{5}{|c|}{ Duration of work (years) } \\
\hline$<2$ & $6(1.48 \%)$ & $20(4.93 \%$ & 1.00 & 1.00 \\
\hline $2-4$ & $30(7.39 \%)$ & $60(14.78 \%)$ & $1.67(0.61$ to 4.59$)$ & $1.87(0.93$ to 6.01$)$ \\
\hline $5-9$ & $55(13.55 \%)$ & $115(28.33 \%)$ & $1.59(0.61$ to 4.41$)$ & $1.71(0.92 \text { to } 5.35)^{*}$ \\
\hline$\geq 10$ & $60(14.78 \%)$ & $60(14.78)$ & 3.33 (1.25 to 8.88$)$ & $3.53(1.75 \text { to } 8.98)^{*}$ \\
\hline
\end{tabular}

$*=$ statistical significant i.e. $\mathrm{p}<0.05$

$\mathrm{COR}=$ Crude Odds Ratio and, $\mathrm{AOR}=$ Adjusted Odds Ratio

\subsection{Relationship with Training and Work Experience}

On studying the variables that could affect KAP scores, it was found that duration of work experience and having ever received training before engaging to this work on prevention of occupational health hazards were significantly related to satisfactory scores of knowledge, favorable scores of attitude and safe scores of practice among waste handlers. The only variable that was not significantly related with knowledge score domain was duration of work/ work experience. The difference in the knowledge of occupational health hazards between the satisfied and the unsatisfied solid waste workers was statistically significant $\left(\mathrm{X}^{2}=73.69, \mathrm{P}<0.001\right)$. Those who had received training had satisfactory knowledge scores $(36.21 \%)$ than those who had not received training $(24.6 \%)(P<0.001)$. Moreover, those who had worked 5- 9 years had safe occupational health practices scores $(13.63 \%)$ than those who had worked 2- 4 years $(7.39 \%)(P<0.004)$ (Table 4$)$. 
Table 4. Relationship of duration of work experience and training of solid waste handlers with knowledge, attitudes and practice scores on prevention of occupational health hazards, 2015.

\begin{tabular}{|c|c|c|c|c|c|c|c|c|c|c|c|c|}
\hline \multirow{3}{*}{ Work Practice } & \multicolumn{4}{|c|}{ Knowledge } & \multicolumn{4}{|c|}{ Attitudes } & \multicolumn{4}{|c|}{ Practices } \\
\hline & \multicolumn{2}{|c|}{ Satisfactory } & \multicolumn{2}{|c|}{ Unsatisfactory } & \multicolumn{2}{|c|}{ Favorable } & \multicolumn{2}{|c|}{ Unfavorable } & \multicolumn{2}{|c|}{ Safe } & \multicolumn{2}{|c|}{ Unsafe } \\
\hline & NO. & $\%$ & NO. & $\%$ & NO. & $\%$ & NO. & $\%$ & NO. & $\%$ & NO. & $\%$ \\
\hline \multicolumn{13}{|l|}{ Received Training } \\
\hline Yes & 147 & 36.21 & 26 & 6.40 & 158 & 38.92 & 15 & 3.69 & 23 & 5.67 & 150 & 36.95 \\
\hline \multirow[t]{2}{*}{ No } & 100 & 24.63 & 133 & 32.76 & 150 & 36.95 & 83 & 20.44 & 14 & 3.45 & 219 & 53.94 \\
\hline & \multicolumn{4}{|c|}{$\mathrm{X}^{2}=73.69, \mathrm{P}<0.001$} & \multicolumn{4}{|c|}{$\mathrm{X}^{2}=39.38, \mathrm{P}<0.001$} & \multicolumn{4}{|c|}{$\mathrm{X}^{2}=6.36, \mathrm{P}<0.012$} \\
\hline \multicolumn{13}{|c|}{ Duration of work (Years) } \\
\hline$<2$ & 17 & 4.19 & 9 & 2.22 & 18 & 4.43 & 8 & 1.97 & 6 & 1.48 & 20 & 4.93 \\
\hline $2-4$ & 60 & 14.78 & 30 & 7.39 & 74 & 18.23 & 15 & 3.69 & 30 & 7.39 & 60 & 14.8 \\
\hline $5-9$ & 100 & 24.63 & 70 & 17.24 & 135 & 33.25 & 35 & 8.62 & 55 & 13.6 & 115 & 28.3 \\
\hline \multirow{2}{*}{$\geq 10$} & 70 & 17.24 & 50 & 12.22 & 81 & 19.95 & 40 & 9.85 & 60 & 14.8 & 60 & 14.8 \\
\hline & \multicolumn{4}{|c|}{$\mathrm{X}^{2}=2.11, \mathrm{P}=0.54$} & \multicolumn{4}{|c|}{$\mathrm{X}^{2}=9.63, \mathrm{P}<0.022$} & \multicolumn{4}{|c|}{$\mathrm{X}^{2}=12.92, \mathrm{P}<0.004$} \\
\hline
\end{tabular}

\section{Discussion}

Four hundred twenty three questionnaires were prepared and about 406 were collected and analyzed giving a response rate of $94.8 \%$, the remaining $5.5 \%$ were not analyzed due to inappropriately filled responses. The response rate of this study was almost similar with studies like 97.9\% (Bogale 2012), 92\% (Mehrdad R, Majilessi-Nasr M et al. 2008) and $95 \%$ (Ahmed 2004). Majority of the respondents were aged between 35 - 44 years $(39.4 \%)$, followed by ages of $25-34$ (23.4\%), the age range of $\geq 55$ years $(6.9 \%)$ recorded the least occurrence(53.9\%). Most of the respondents were illiterate/ and read and write $(53.9 \%)$. This was similar with a study done in Egypt: that majority of MSW collectors (78.3\%) were above the age of 40 and most of the MSW collectors $(89.2 \%)$ were illiterate/read and write (Abou-ElWafa HS, ElBestar SF, El-Gilany A-H, et al. 2015). Two hundred and eighty three $(69.7 \%)$ of respondents were females while 123 $(30.3 \%)$ were males. Number of female solid waste collectors was higher as compared with some other studies those either with no or small number of female workers in this sector (Mudalige OM and Dharmathilake AD 2000; Mehrdad R, Majilessi-Nasr $M$ et al. 2008; Halim and et al 2011). The main reason for large number females in this study might be due to the sectors' being an emerging and leveled as one of small scale enterprises in the country and females are actively involved in this sector. According to (Adogu et al. 2015), the predominance of female respondents might be is a reflection of higher level of interest to engage in this work. The current study also revealed that a sizeable number of the respondents $151(37.2 \%)$ had no education/ illiterate, primary and secondary school education (grade 5 -12) together account 106 (26.1\%), and the remaining 149 (36.7\%) had attend only grade 1- 4 schooling, this is an indication of a low level of educational status. This is unlike the work done by Adogu et al. on waste management practices of residents in Nigeria which showed that only about $8.5 \%$ of the respondents had no formal education, $60.3 \%$ attained tertiary level education and $19.9 \%$ attained secondary level education, while $11.4 \% \%$ had primary education (Adogu et al. 2015). Consequently, the low level of safe occupational health practices $151(37.2 \%)$ of waste handlers in this study could be explained by the generally low educational status of respondents.

The percentage of waste handlers who had received training before engaging to this line of work in this study was $42.6 \%$ which is greater when compared with other studies done in Addis Ababa, Ethiopia, 6\% (Tadesse G March 2007) and 20.8\% (Bogale 2012). This might be due to involvement of stack holders' like micro and small scale development office, different non-government organizations and solid waste management office. Having supervising to solid waste handlers on occupational health and safety matters was not significantly associated with occupational health risk preventing practices in this study. This was not inline with other studies done in Addis Ababa (Tadesse G March 2007). About $35.5 \%$ of solid waste handlers participated in this study were eating at work place which is similar with a study done in Addis Ababa 33.7\% (Tadesse G March 2007). Hand washing practice is the single most important means of preventing spread of infection (Abash s, Ohimain E, 2011). The respondents in this study had hand washing habit with soap after waste collection (78.1\%) which is higher when compared to other study conducted in Addis Ababa 27.7\% (Tadesse G March 2007), These result was better than hand hygiene practices report in North wollo, 28.3\% (Damte M, 2006) but similar with finding in Nigeria 79\% (Abash $\mathrm{s}$, Ohimain E, 2011). The difference might be due to, many of the workers in this study had satisfactory knowledge about preventing occupational health hazards.

The overall knowledge of solid waste handlers about prevention of occupational health hazards was better compared to their practices. The safe occupational health practice was low on all counts among sanitary workers; this was similar to the findings from other studies (Tadesse G March 2007). Workers having satisfactory level of knowledge about the hazards associated with their work in the present study $(60.8 \%)$ were much higher than the carpenters studied by Bolaji in Nigeria (15.4\%) (Bolaji, 2005). This difference might be due to different in the study participants (solid waste handlers vs carpenters). The attitude 
of solid waste handlers towards prevention of occupational health hazards was a matter of concern. Low level of safe occupational health practices is mainly attributed to poor training facilities and also to low educational level of the solid waste handlers in this study. Training of solid waste handlers is critical for the proper and appropriate occupational health practice. Wearing glove among Lideta sub city solid waste handlers was higher than previous studies done in Addis Ababa 39\% (Bogale 2012) and 37.6\% (Tadesse G March 2007). This might be due to involvement of different non-government organizations on supplying PPEs for waste handlers. Even if the quality of the gloves is not the right item and most of the gloves were old, perforated and not using appropriately.

In this study the variables age, sex, years of education, received training about the job-associated hazards, duration of work overall level of knowledge and job satisfaction were the most important predictors of the workers' occupational health practice about the occupational hazards. However, the variable sex and age had no statistically significant effect on the occupational health practice of the workers. Workers who were satisfied on their job had 2.8 times more safe occupational health practices $(\mathrm{AOR}=2.8,95 \% \mathrm{CI}: 1.84$ 4.26). The difference in the occupational health practices of illiterate and grade 5-12 waste workers was statistically significant. Those who were grade 5-12 had 1.14 times more safe occupational health practices than the illiterate waste workers $(\mathrm{AOR}=1.14,(95 \% \mathrm{CI}: 1.01-2.55)$. This study tried to reduce recall bias by asking occurrence of occupational health hazards in the last one year and one month prior this data collection. However, it is impossible to avoid recall bias totally. This study did not report about the important risks such as hepatitis B and hepatitis A virus infection of the waste collectors. In addition to these, cause and effect relationship might not be established due to the crosssectional nature of the study.

\section{Conclusion and Recommendations}

- The result of this study revealed that the magnitude of safe occupational health practice among solid waste collectors was very low while the overall level of knowledge and attitudes were high/moderate.

- The variables which had significant influence on the practice of workers about occupational health hazards were years of education, received training about the job-associated hazards, duration of work and job satisfaction. These variables should be taken into consideration in any program addressing occupational health and safety issues.

- Lideta sub-city solid waste management office should provide occupational health and safety training, support and supervise woreda solid waste management offices on occupational health and safety.

- Policy makers should enforce training occupational health and safety before engaging to waste collection job for every waste collector.

\section{Acknowledgments}

Acknowledgement is made to College of Health Sciences, Addis Ababa University for supporting the study financially. Our sincere gratitude would also go to all our friends who were willing to give really their constructive comments and support in any kind. We sincerely thank the Lideta Sub-city Administration Health Office and the study participants for their unreserved cooperation during data collection time.

\section{References}

[1] Abash s, Ohimain E. (2011). Healthcare waste management in Nigeria: A case study. Journal of Public Health and Epidemiology, Vol. 3(3), pp. 99-110.

[2] Abou-ElWafa HS, El-Bestar SF, El-Gilany A-H, et al. (2012). Musculoskeletal disorders among municipal solid waste collectors in Mansoura, Egypt: a cross-sectional study. BMJ Open; 2(5).

[3] Addis Ababa city solid waste management Agency (February 2010). "Over view of Addis Ababa City solid waste management system".

http://www.un.org/esa/dsd/susdevtopics/sdt_pdfs/meetings201 0/icm0310/2b-2_Tessema.pdf

[4] Adogu, P. O. U., Uwakwe, K. A., Egenti, N. B., et al. (2015) Assessment of Waste Management Practices among Residents of Owerri Municipal Imo State Nigeria. Journal of Environmental Protection, 6, 446-456. http://dx.doi.org/10.4236/jep.2015.65043

[5] Ahmed, K. (2004). "Investigation of Occupational health and safety hazards among domestic waste collectors Bethlehem and Hebron district" An -najah university press Nablus.

[6] Bogale, D. (2012). Assessment of Occupational injuries and illness symptums among Addis Ababa City Solid waste collectors.

[7] Bolaji AO. (2005). Analytical study of carpenters' attitude towards safety and occupational health practice in Oyo state of Nigeria. J Ecol.; 18(2): 99-103.

[8] Damte M. (2006). Assessment of knowledge, attitude and practice of $\mathrm{HCW}$ on universal precaution.

[9] Direct initiative for social and health action (2009). "A rapid assessment survey of health and environmental impacts of solid waste recycling."

[10] Federal Ministry of Health of Ethiopia (December 2010). Ethiopia national expanded programme on immunization: Comprehensive multi-year plan 2011 - 2015, Addis Ababa, Ethiopia.

http://www.gavi.org/Country/Ethiopia/Documents/CMYPs/Co mprehensive-multi-year-plan-for-2011$2015 /+\& \mathrm{~cd}=1 \& \mathrm{hl}=$ en $\& \mathrm{ct}=\mathrm{clnk} \& \mathrm{gl}=$ et

[11] Hafiz O. Alhmed, Mark S. Newson-Smith. (2010). Knowledge and Practices Related To Occupational Hazards Among Cement Workers In United Arab Emirates. J Egypt public health Assoc, vol. 85 (3).

[12] Halim and et al (2011). "Respiratory functions of the people working in solid waste storage centers." in Istanbul. Nobel Medicus 7(1): 29-36. 
[13] ILO, Ed. (2003). Environmental and social guidelines for occupational health and safety in ILO.

[14] International Labour organization (2001). "Working conditions and Environment a workers education manual."

[15] Inyang M (2009) Health and safety risks among the municipal solid waste collectors in Port Harcourt metropolis of the Niger delta region of Nigeria. International conference waste management, environmental geotechnology and global sustainable development.

[16] Kiwekete HM (2009). "A role of safety culture in preventing accidents in the work place." Afr Newsletter on occupational health and safety 19(1): 20-21.

[17] M. Athanasiou, G. Makmxnes, et al. (5 September 2010). "Respiratory Health of municipal solid waste workers." Occupational Medicine advance access publication 10(1093).

[18] Mehrdad R, Majilessi-Nasr M, et al. (2008). "Musculoskeletal disorders among municipal solid waste workers." Actamedical Iranica 46(3): 233-238.

[19] Mola S (2005). Occupational Health and safety training package for solid waste handlers Addis Ababa Addis Ababa, Addis Ababa city Solid waste Management Agency.

[20] Mudalige OM and Dharmathilake AD (2000). Health problem among Colombo municipal council workers, AL 2000 batch of students. Univesity of Colombo press. Colombo, Colombo University.

[21] Oxford university (2005). "occupational medicine." society of occupational medicine.

[22] Oyelola OT and Babatunde A (2009). "Health implications of solid waste disposal."

[23] Phiman E (2011) Health risk reduction behavior model for scavengers exposed to solid waste in municipal dump in Nakhon Ratchasima province.

[24] S., C. (2005). private sector participation in municipal solid waste management, guidance pack. Skat Switzerland.

[25] Sarkar, p. (2003). "Solid waste Management in Delhi a solid vulnerability study".

[26] Tadesse G (March 2007). "The baseline survey of the occupational safety and health conditions of solid waste primary collectors and street sweepers in Addis Ababa."

[27] Tiwari R (2008). "occupational health hazards in sewage and sanitary workers." Indian Journal of occup med.

[28] WHO (1998). "Strengthening of health surveillance of working populations the use of International statistical classification of diseases (ICD-10) in occupational health." 